\title{
Peptidase activities in Crotalus durissus terrificus semen
}

\author{
Camila Eduardo Marinho ${ }^{1,4}$, Selma Maria Almeida-Santos ${ }^{2}$, Sylvia Mendes Carneiro ${ }^{3}$, Simone \\ Cristina Yamasaki ${ }^{1}$ and Paulo Flavio Silveira ${ }^{1}$ \\ ${ }^{1}$ Laboratory of Pharmacology, ${ }^{2}$ Laboratory of Ecology and Evolution and ${ }^{3}$ Laboratory of Cellular Biology, Instituto \\ Butantan, Av. Vital Brasil, 1500, São Paulo SP 05503-900, Brazil and ${ }^{4}$ Department of Physiology, Instituto de \\ Biociências, Universidade de São Paulo, São Paulo SP 05508-900, Brazil
}

Correspondence should be addressed to P F Silveira; Email: pefesil@butantan.gov.br

\begin{abstract}
To understand the role of peptidases in seminal physiology of Crotalus durissus terrificus, activity levels of representative enzymes in semen and their sensitivities to inhibitors, cofactors, and peptide hormones were evaluated. The existence of seminal fractions and the association of peptidases with these fractions were also characterized for the first time in snakes. The prominent inhibitors of aminopeptidases (APs) were amastatin for acid, basic, and neutral; bestatin for basic; and diprotin A for dipeptidyl-IV. Cystyl and prolylimino APs were similarly susceptible to the majority of these inhibitors. The basic and neutral were characterized as metallo-peptidases, acid AP was activated by $\mathrm{MnCl}_{2}$, and cystyl, prolyl-imino, and type I pyroglutamyl were characterized as sulphydryl-dependent APs. Angiotensin II, vasotocin, bradykinin, fertilization-promoting peptide, and TRH altered the majority of these peptidase activities; these peptides are possible substrates and/or modulators of these peptidases. Peptidase activities were found in all seminal fractions: seminal plasma (SP), prostasome-like (PR) structures, and soluble (S-) and membrane-bound fractions (MFs) of spermatozoa. The levels of activity of each peptidase varied among different seminal fractions. In SP, the higher activities were puromycin-insensitive neutral and basic APs. In PR, the higher activity was puromycin-insensitive neutral AP. In spermatozoa, the higher activity in subcellular SF was puromycinsensitive neutral, while in MF both puromycin-sensitive and -insensitive neutral APs were equally higher than the other examined peptidases. Data suggested that these peptidases, mainly basic and neutral, have a high relevance in regulating seminal functions of C. d. terrificus.

Reproduction (2008) $136767-776$
\end{abstract}

\section{Introduction}

Enzyme hydrolysis leading to inactivation or processing of peptides has been assumed to be a limitation step for their biological activities. Many peptides, such as angiotensins (Angs; Fraser et al. 2006), kinins (Blaukat 2003), substance P, enkephalins (Sastry et al. 1991), endorphin (El-Haggar et al. 2006), oxytocin (OXT), vasopressin (AVP; Assinder et al. 2000), LHRH (Amory \& Bremner 2003), TRH, and fertilization-promoting peptide (FPP; Green et al. 1996), as well some peptidases, particularly aminopeptidases (APs) and oligopeptidases have been related to seminal physiology in mammals (Fernández et al. 2002, Irazusta et al. 2004, Valdivia et al. 2004, Subirán et al. 2008). In this sense, Ang I and II are hydrolyzed by acid AP (APA; EC 3.4.11.7; Kugler 1982) and, also, by prolyl oligopeptidase (POP; EC 3.4.21.26; Barret et al. 1998). The formation of Ang IV from Ang III (Kugler 1982) and bradykinin (BK) from kallidin (Mizutani et al. 1993) is catalyzed by neutral AP (APN). Enkephalin is hydrolyzed by puromycin-insensitive APN (APN-PI; E.C 3.4.11.2) and puromycin-sensitive APN (APN-PS, E.C 3.4.11.14; Fernández et al. 2002). Substance P, enkephalin, BK, OXT, AVP, LHRH (Barret et al. 1998), TRH, and FPP (Siviter \& Cockle 1995) are hydrolyzed by POP. OXT and AVP are hydrolyzed by cystyl AP (CAP, EC 3.4.11.3; Davison et al. 1993). LHRH and TRH are susceptible to type I pyroglutamyl AP (PAP-I, EC 3.4.19.3; Cummins \& O'Connor 1998), and FPP is a possible substrate of this enzyme. BK, kallidin, met-enkephalin, and somatostatin are hydrolyzed by basic AP (APB, EC 3.4.11.6; Barret et al. 1998). Substance Pand endorphin2 are substrates of dipeptidyl peptidase-IV (DPPIV, EC 3.4.14.5; Barret et al. 1998).

The distribution of peptidases in seminal fractions is fundamental to the regulatory role of these enzymes. Until the present, earlier studies of human seminal fractions evaluated the distribution of only three of the above-mentioned peptidases: APN (Fernández et al. 2002, Subirán et al. 2008), PAP, and POP (Valdivia et al. 2004). APN was detected in soluble (S-) and solubilized membrane-bound fractions (MFs) of seminal plasma (SP) and prostasomes (PRs; Fernández et al. 2002). In sperm, APN was detected in the equatorial segment of the upper post-acrosomal region of the head, in the neck, and 
along the tail (Subirán et al. 2008). Alterations of APN levels in human semen were associated with different abnormalities in the sperm of subfertile patients (Irazusta et al. 2004). PAP-I and POP activities were detected in SP and in the PR fraction, as well as in soluble and membrane-bound sperm subcellular fractions, and have higher activities in necrozoospermia than in normozoospermic semen (Valdivia et al. 2004). AP and amylase activities are also known to be the main agents in the liquefaction process of the ejaculated semen coagulum, in humans (Chatterjee et al. 1997). Moreover, AP inhibitors, bestatin and puromycin, are capable of diminishing cellular proliferation and viability in mammals (Takahashi et al. 1989, Constam et al. 1995). However, bestatin is capable of restoring and promoting follicular growth and ovulation after its suppression by stress (Nakamura et al. 1998).

To our knowledge, the fractionation of semen and the presence of seminal APs and POP have not yet been studied in snakes. Furthermore, species possessing sperm with long lifespans, such as the rattlesnake Crotalus durissus terrificus, are interesting experimental models to study the distribution and function of peptidases in seminal fractions. In $C$. $d$. terrificus, spermatogenesis begins in spring and has its peak in summer. The spermatozoa are maintained in the male tract until mating (middle of autumn; Almeida-Santos et al. 2004) and, subsequently, in the female tract until ovulation (spring; Almeida-Santos \& Salomão 1997). The goal of the present study was to evaluate the existence of mammalian-like seminal fractions (SP, PR, and sperm), and to characterize the activity levels of soluble and membranebound APA, APB, APN-PI, APN-PS, CAP, PAP-I, DPPIV, $\mathrm{POP}$, and prolyl iminopeptidase (PIP) and their sensitivities to inhibitors, cofactors, and possible natural substrates in whole semen, as well as their associations with different seminal fractions of $C$. $d$. terrificus.

\section{Results}

Figure 1 shows that lactate dehydrogenase (LDH) activity in SF was threefold higher than in MF of whole semen. Similar proportion was obtained in spermatozoa subcellular SF and MF (data not shown).

Table 1 shows values of peptidase activity in SF and MF of whole semen. APB, PIP, and POP activities were detected only in $\mathrm{SF}$, while the others were detected in SF and MF.

Table 2 shows that APB activity was markedly inhibited by amastatin and bestatin, APA and APN by amastatin, and diprotin A had a stronger effect on DPPIV activity in SF and MF. CAP and PIP activity decreased in the presence of majority of examined inhibitors. Bestatin and puromycin were more efficient to inhibit PAP. POP activity was not evaluated by classical AP inhibitors, since it is an endooligopeptidase (the only one under study here), and this activity was shown to be increased

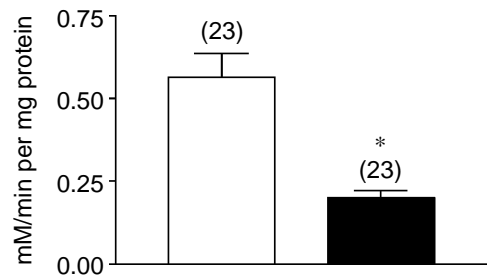

Figure 1 LDH activity (means \pm s.E.M.) in soluble (white bar) and solubilized membrane-bound (black bar) fractions of whole semen of C. $d$. terrificus. Number of animals is given in parentheses. ${ }^{*} P<0.0003$ (unpaired two-side Student's $t$-test).

or indifferent with the adopted agents (Olivo et al. 2008). CAPactivity in SF, PAP-I, and PIP had a common pattern of decrease with $\mathrm{BK}, \mathrm{TRH}$, and FPP (with or without $\mathrm{Ca}^{2+}$ ). Ang II and BK diminished APA activity in SF and MF. Ang II and arginine vasotocin (AVT) decreased CAPactivity in SF and PIP activity. AVT also decreased CAP activity in MF. DL-dithiothreitol (DTT) improved CAP activity in SF and MF and PIP activity, and decreased APB activity. EDTA diminished the activities of APB and APN SF and MF. $\mathrm{MnCl}_{2}$ decreased the activities of CAP in MF, PAP, and DPPIV SF and MF, and increased APA activity.

As shown in Fig. 2, a peak coincided with the dead volume (Vo) of seminal fraction from gel filtration in Sephadex G-200. This peak was analyzed by transmission electron microscopy and had numerous rounded or oval membranous vesicles of the size 50-200 nm, shown in Fig. 3.

Figure 4 shows AP activities in seminal fractions: SP, $\mathrm{PR}$, and spermatozoa subcellular SF and MF. In SP, the higher activities were $\mathrm{APN}-\mathrm{PI}$ and $\mathrm{APB}$ relative to other examined peptidases. In PR, APN-PI activity also had the higher level, followed by APB and APN-PS. In spermatozoa subcellular SF, APN-PS activity was higher, while in spermatozoa subcellular MF, APN-PS and APN-PI

Table 1 Activity levels of aminopeptidases: acid (APA), basic (APB), puromycin-insensitive neutral (APN-PI), puromycin-sensitive neutral (APN-PS), dipeptidyl peptidase-IV (DPPIV), pyroglutamyl-I (PAP-I), prolyl-imino (PIP); and prolyl oligopeptidase (POP) in soluble (SF) and solubilized membrane-bound (MF) fractions of whole semen of Crotalus durissus terrificus.

\begin{tabular}{lcc}
\hline & \multicolumn{2}{c}{ Activities (U/mg protein) } \\
\cline { 2 - 3 } Aminopeptidase & SF & MF \\
\hline APA & $691 \pm 180^{\mathrm{a}}(16)$ & $838 \pm 229^{\mathrm{a}}(16)$ \\
APB & $18549 \pm 3227^{\mathrm{b}, *(15)}$ & Absent \\
APN-PI & $30372 \pm 317^{\mathrm{c}}(13)$ & $23866 \pm 1938^{\mathrm{b}}(13)$ \\
APN-PS & $9019 \pm 1133^{\mathrm{d}, *(10)}$ & $12637 \pm 1290^{\mathrm{c}}(11)$ \\
CAP & $31 \pm 14^{\mathrm{a}}(14)$ & $30 \pm 13^{\mathrm{a}}(15)$ \\
DPPIV & $234 \pm 57^{\mathrm{a}, *(13)}$ & $560 \pm 153^{\mathrm{a}}(11)$ \\
PAP-I & $261 \pm 34^{\mathrm{a}}(14)$ & $231 \pm 71^{\mathrm{a}}(16)$ \\
PIP & $257 \pm 66^{\mathrm{a}, *(15)}$ & Absent \\
POP & $1777 \pm 252^{\mathrm{a}, \mathrm{d}, *(14)}$ & Absent \\
\hline
\end{tabular}

Values are means \pm S.E.M. Number of animals is given in parentheses. $\mathrm{U}=$ picomoles of hydrolyzed substrate per minute. Different letters indicate different peptidase activity levels in the same fraction (Oneway ANOVA $P<0.0001$, Bonferroni $P<0.05$ ). ${ }^{*} P<0.05$ in comparison to MF (unpaired, two-side Student's $t$-test). 


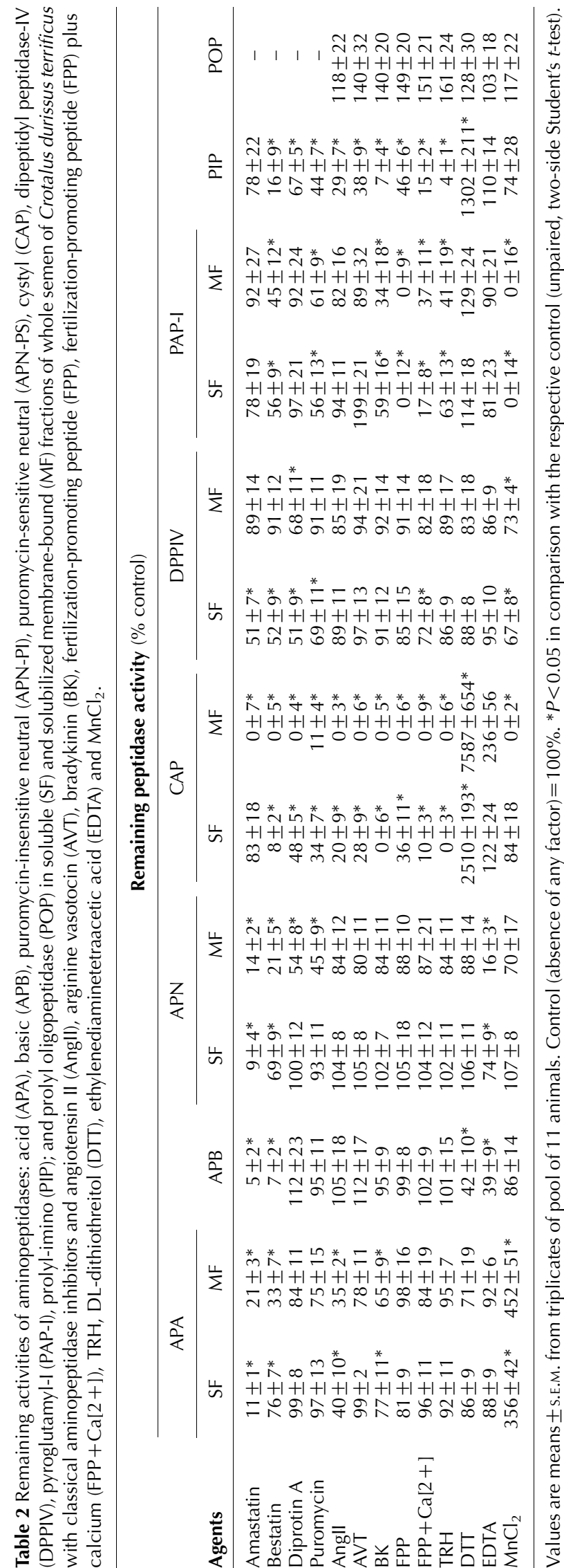

activities were higher than other examined peptidase activities. Considering activity levels of each peptidase among different seminal fractions, $\mathrm{APB}, \mathrm{PIP}$, and $\mathrm{POP}$ were higher in SP; APB, APN-PI, DPPIV, and PAP-I in PR; APN-PS in spermatozoa subcellular SF; and PAP-I and CAP in spermatozoa subcellular MF. APA was equally distributed among all seminal fractions. It was noteworthy that APN-PS activity was absent in SP.

\section{Discussion}

The efficiency of the employed procedure to separate SF and MF was confirmed by the pronounced LDH activity (cytosolic marker) in SF of all samples, which allowed the characterization of the activity of each peptidase in different fractions, and consequently the association of intra- and extracellular peptides with the peptidase activities under study. Overall, peptides involved in intracellular signaling are primarily hydrolyzed outside the cell, mainly by membrane-bound peptidases which have, in general, the active sites in the extracellular side, which interact with released peptides (O'Cuinn 1998). Soluble peptidases act mainly in intracellular processes, but can also be exocytosed or act in recaptured peptides, which are internalized as a part of the peptide-receptor complex, as occurs with peptide hormones (Gibson et al. 1989). Under stimulation, cytosolic enzymes can be translocated to the cell surface and efficiently process extracellular substances (Albiston et al. 2004). In the present study, APB, PIP, and POP activities were detected only in SF and the other activities were detected in SF and MF, following the same pattern found in tissues and semen of mammals (Irazusta et al. 2001, 2004, Silveira et al. 2001, Varona et al. 2003).

The use of substances derived from naphthylamide has been the initial step to detect or confirm the involvement of APs and POP in physiological mechanisms. Variables that could not be controlled might have influenced peptidase activities in the present study, e.g. intra-season and geographical and circadian variations. This is possible considering the seasonality, since samples were obtained in different days of the same season (austral autumn - the mating season for $C$. d. terrificus). However, the fertility potential of semen can be presumed effective and homogeneous along this season, based on the existence of a high quality of seminal dynamic parameters of Boa constrictor occidentalis (Tourmente et al. 2007), the peak of testosterone (Zacariotti et al. 2005) and the decrease of spermatozoa defects (Zacariotti 2004) in C. d. terrificus. Geographical variation was not a factor as snakes were captured from locations with similar fauna and environmental conditions. Moreover, we can also exclude circadian variations, because the material was obtained in the same period of the day, with a maximum difference of $90 \mathrm{~min}$. 


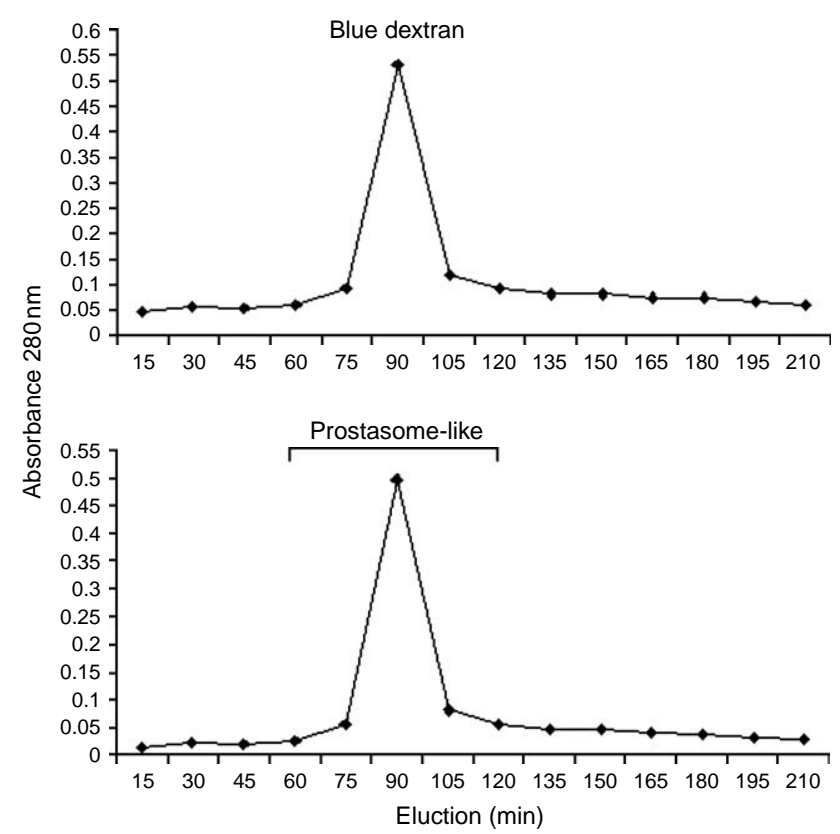

Figure 2 Gel filtration chromatography on Sephadex G-200. The column was equilibrated and washed with Tris-saline buffer $(30 \mathrm{mM}$ Tris plus $130 \mathrm{mM} \mathrm{NaCl}$ ), $\mathrm{pH} 7.4$, flow rate $0.16 \mathrm{ml} / \mathrm{min}$.

The anatomy and morphology of the male reproductive tract could also influence the features of the peptidase activities and their distribution in seminal fractions of $C . d$. terrificus. In reptiles, the ductus deferens are recognized as the site of spermatozoa storage in males and, differently from mammals, the epididymis does not participate in sperm maturation and storage (Sever et al. 2002). The ductus deferens of $C$. $d$. terrificus are convoluted and enter the cloaca independently of the ureters. As previously described by Almeida-Santos et al. (2004), the ductus deferens occupy about one-third of the body length and when freed from

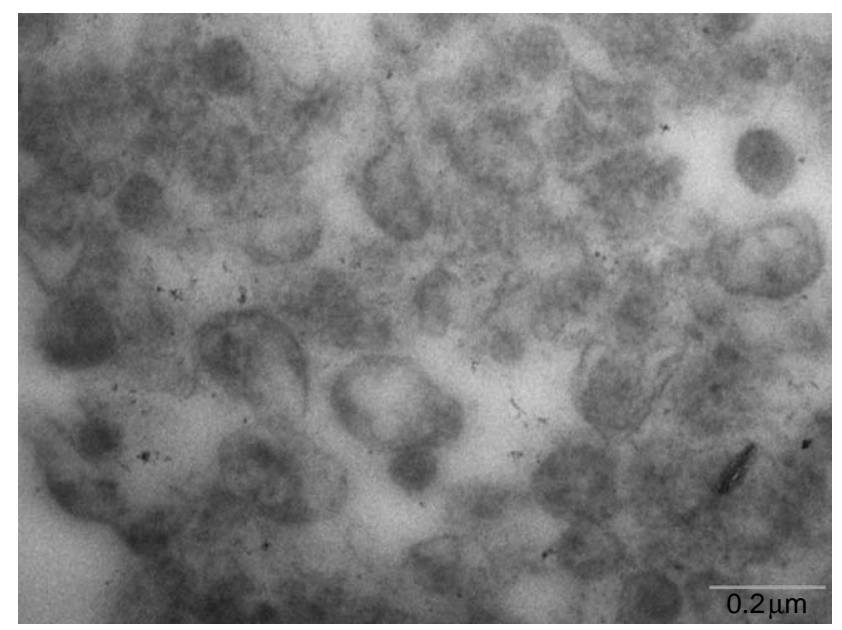

Figure 3 Electron microphotography of prostasome-like structures from semen collected from the ductus deferens of $C$. $d$. terrificus in austral autumn. the peritoneal membrane and manually distended, its length is about six times the total body length, although the right duct is always slightly longer than the left. Three regions can be distinguished: proximal (testicular), median, and distal (cloacal). In this snake, spermatozoa become increasingly more motile from the proximal to the distal region (Almeida-Santos et al. 2004). Regarding the presence of examined peptidase activities in the spermatozoa, the identification of their anatomical sources need to be investigated; for example, in the acrosomal complex, which is known in all vertebrate taxa as an enzyme-rich organelle that facilitates spermatozoal penetration into the ovum (Subirán et al. 2008). In squamates, the acrosomal complex is highly compartimentalized (Gribbins et al. 2007), and this compartimentalization has been suggested as an aid to the sequential release of acrosomal enzymes (Talbot 1991). Since the scope of the present study was not to compare the seminal fractions and peptidase composition from different areas of the ductus deferens, semen from the entire ductus deferens of $C$. $d$. terrificus was taken systematically to assure similar seminal fluid components for each analysis.

The APs under study are known to be sensitive to amastatin, bestatin, diprotin A, and puromycin (Cadel et al. 1995, Ronai et al. 1999, Sato 2003). POP is inhibited by Z-Pro-prolinal (García-Horsman et al. 2007) and belonging to a distinct class of enzymes, it was not included in the inhibition assay.

In the present study, APB susceptibility to bestatin distinguished this enzyme from APA and APN. By the susceptibility of DPPIV to diprotin A, and PAP-I, CAP, and PIP to puromycin, it was possible to differentiate them from APA and APB. The inhibition of DPPIV by diprotin $A$ is a known feature of this enzyme (CD26) in mammals (Minelli et al. 1999). As distinguishing features, APB and APN are metallo-peptidases, because of their inhibition by EDTA (Kawata et al. 1980). APA was marked as activated by $\mathrm{MnCl}_{2}$, which is a known characteristic of this enzyme in mammals (Ramírez et al. 1990). CAP and PAP-I were activated by DTT, a thiol-reducing agent, characterizing them as sulphydryldependent peptidases. DTT is an activator of the type I PAP and an inhibitor of the type II (O'Cuinn et al. 1990), and the degradation of FPP (possible substrate of PAP-I) is also increased by the presence of DTT (Cockle et al. 1994), which confirms that PAP-I is among the enzymes studied in the present work and FPP is one of its substrates. Overall, the present results show that seminal peptidase activities of $C$. $d$. terrificus have distinct biochemical properties, and therefore it is possible to attribute them to different proteins. It was notable that enzyme activities were affected by the evaluated peptides, which are their possible substrates (e.g. Ang II on APA, AVT on CAP, and PIP, and particularly TRH and FPP with or without $\mathrm{Ca}[2+]$ on CAP, PIP, and PAP-I). These results indicate the competition among these 

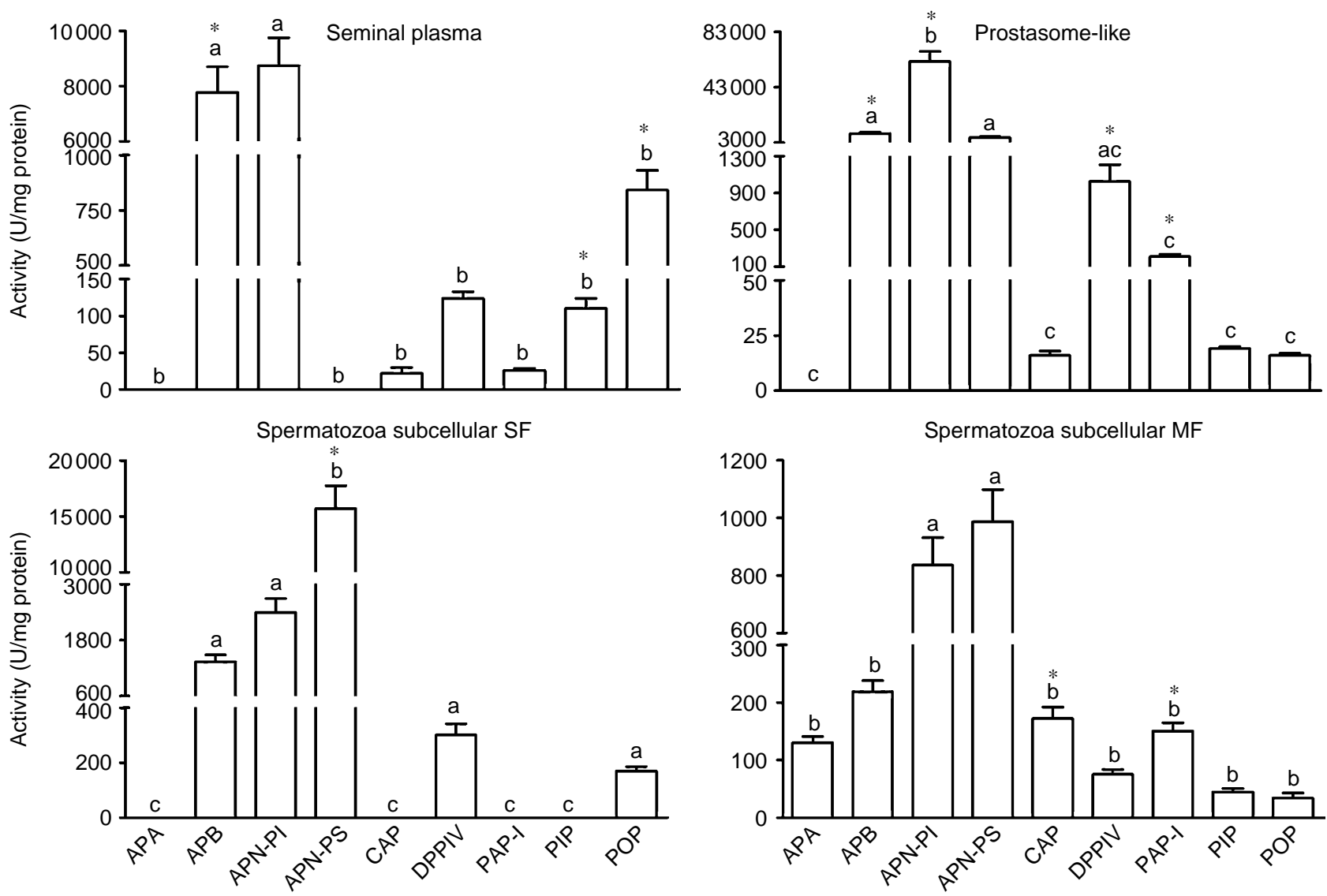

Figure 4 Distribution of activity levels of aminopeptidases: acid (APA), basic (APB), puromycin-insensitive neutral (APN-PI), puromycin-sensitive neutral (APN-PS), cystyl (CAP), dipeptidyl peptidase-IV (DPPIV), pyroglutamyl-I (PAP-I), prolyl-imino (PIP); and prolyl oligopeptidase (POP) in seminal plasma, prostasome-like and spermatozoa subcellular soluble (SF) and solubilized membrane-bound (MF) fractions of $C$. $d$. terrificus. Values are means \pm s.E.M. from triplicates of samples (see Materials and Methods). $U=$ picomoles of hydrolyzed substrate per min. Different letters indicate different peptidase activity levels in the same fraction (one-way ANOVA, $P<0.0001$, Bonferroni $P<0.001$ ). Asterisks indicate the higher activity of each peptidase when comparisons were made among all seminal fractions (one-way ANOVA, $P<0.0003$, Bonferroni $P<0.05$ ).

peptides and the synthetic substrates, strongly suggesting that those peptides are natural substrates of seminal peptidases of $C$. $d$. terrificus.

The semen of the rattlesnake contains SP and spermatozoa, as well as vesicles resembling mammalian PRs. Although ulterior ultrastructural analyses are needed to determine peculiarities of these vesicles seen in $C . d$. terrificus, compared with PRs of mammals, they could be considered as PR structures since they were obtained by the same purification procedure employed to obtain human PRs (Fernández et al. 2002, Vivacqua et al. 2004) and had peptidase activities (Fernández et al. 2002), shape (Fernández et al. 1997, Vivacqua et al. 2004), and size (Olsson \& Ronquist 1990, Vivacqua et al. 2004) similar to human PRs. Mammalian PRs are membranous vesicles $(50-550 \mathrm{~nm} ; 150-200 \mathrm{~nm}$ are the most frequent), which contain large amounts of cholesterol, sphingomyelin, calcium, and several enzymes (Kravets et al. 2000). They are surrounded by a bilaminal or multilaminar lipoprotein membrane with unusual lipid composition due to quantitative predominance of cholesterol over phospholipids (Kravets et al. 2000). PRs have been related to sperm motility, liquefaction, and immunosuppression (Kravets et al. 2000). Since PRs can be identified only after purification procedures it is difficult to infer how frequent they are in $C . d$. terrificus. Another important question that remains to be investigated is the origin of these vesicles in C. d. terrificus. In humans, PRs are secreted by the prostate gland (Kravets et al. 2000). In bovines, PRs are originated in the seminal vesicles (Agrawal \& Vanha-Perttulla 1987). Seminal vesicles secrete proteins, vitamin $\mathrm{C}$, fructose, prostaglandin, and fibrinogen, while the prostate gland secretes a whitish liquid with low viscosity which contains citrate and $\mathrm{Ca}^{2+}$ (Minelli et al. 1998). It is noteworthy that $C$. $d$. terrificus possesses PR structures, since squamates do not possess a prostate gland, seminal vesicles, and bulbo-urethral and urethral glands (Sever 2004). The renal sexual segment is known to act as an accessory sex organ (Sever et al. 2002), from which those structures could have originated. This renal sexual segment of snakes secretes a complex of glycogen, 
mucopolysaccharides, lipids, mucoproteins, and phosphatases (Kühnel \& Krisch 1974) in a pattern that can be related to spermatogenic cycle and mating activity (Sever et al. 2002). However, since in the present study the semen was collected from the ductus deferens, it would not have mixed with fluids from the renal sexual segment but probably from other areas of major secretory activity in the snake urogenital system, e.g. the ampulla ductus deferentis and the ductuli epididymides of the epididymis (Volsoe 1944), from which the PR structures could have originated. The ductuli epididymides or ductuli efferents have been observed in the snake Seminatrix pygaea as efferent ducts from seminiferous tubules of the testis that lead into the epididymis, from which sperm pass into the ductus deferens (Sever 2004). In several mammals, the terminal portion of the ductus deferens is differentiated into an ampulla, which is considered a multifaceted organ, morphologically similar to the seminal vesicles (Riva et al. 1982). Among reptiles, the ampulla has been reported only in squamates, being more prominent in lizards than in snakes (Akbarsha et al. 2005). The ampulla of squamates and mammals shares the irregular narrow folded epithelium (Sever 2004).

The higher levels of the majority of the examined peptidase activities were found in SP and PR fractions. APN and APB activities were more expressive in all seminal fractions. The conversion of kallidin to BK (Mizutani et al. 1993) and inactivation of BK (Barret et al. 1998) are, respectively, actions of APN and APB, indicating the importance of the regulation of these peptides to seminal function in $C$. $d$. terrificus. However, considering our results and the large range of peptides that are susceptible to these peptidases, it is not possible to assure that the high levels of peptidases are restricted only to the kinin system. In other words, the relevance of other evaluated peptidases cannot be ignored. For instance, DPPIV and POP activities were also highly expressed in PR and SP of $C$. $d$. terrificus respectively. Considering their known hydrolytic effects over endorphin-2 and enkephalin, respectively (Barret et al. 1998), and the fact that endogenous opioid peptides seem to have a marked role in seminal physiology (O'Hara et al. 1994, Agirregoitia et al. 2006), DPPIV and POP activities may have a relevant role in seminal physiology of $C$. $d$. terrificus.

In conclusion, this is the first report of fractionation and peptidase composition of semen of reptiles, and demonstrated the presence of acid, basic, neutral (puromycin-sensitive and -insensitive), cystyl, dipeptidyl-IV, type I pyroglutamyl, and prolyl-imino APs, as well as POP activities in SP, spermatozoa, PR structures, and whole semen from ductus deferens of $C$. $d$. terrificus. Metallo-dependent APs inhibited by amastatin and bestatin (mainly those that act on neutral or basic amino acids) had marked levels in whole semen and in all seminal fractions, indicating a high physiological importance. Ang II, AVT, BK, FPP, and TRH altered the majority of the peptidase activities under study, suggesting them as possible substrates and/or modulators of these peptidases.

\section{Materials and Methods}

\section{Animals}

Adult male snakes (C. d. terrificus, Serpentes, Viperidae, Crotalinae; $n=26$ ) were captured from their natural environment in the states of São Paulo and Minas Gerais (Brazil) during austral autumn, when testosterone is at its peak (Zacariotti et al. 2005) and mating occurs (Almeida-Santos \& Salomão 1997). The animals were identified by the Laboratory of Herpetology of the Instituto Butantan and housed individually in wooden cages (inside length $\times$ width $\times$ height of $35 \times 26 \times 22 \mathrm{~cm}$ ) and acclimated to controlled conditions of temperature $\left(25^{\circ} \mathrm{C}\right)$, humidity $(65.3 \pm 0.9 \%)$, and photoperiod $(12 \mathrm{~h}$ light: $12 \mathrm{~h}$ dark-lights on at $0600 \mathrm{~h}$ ) in a restricted-access room for a period of 10 days.

After anesthesia with $\mathrm{CO}_{2}$ exposure for $3 \mathrm{~h}$, the ductus deferens of the reproductive tract were removed by laparotomy (Langlada et al. 1994), and semen was obtained from these ducts. The animals were then destined for other studies after euthanizing by decapitation.

The animal and research protocols used in this study are in agreement with the Brazilian Council Directive (COBEABRAZIL) and were approved by the Ethics Committee of the Instituto Butantan (193/04).

\section{Collection of C. d. terrificus semen}

As previously described by Almeida-Santos et al. (2004), the ductus deferens were stretched out on polystyrene plates for semen extraction. Pressure with a cell scraper (TPP - Techno Plastic Products AG, Trasadingen, Switzerland) along the whole extension of the two ducts was applied. The total amount of semen obtained was used for the following procedures.

\section{Preparation of soluble and solubilized membrane- bound fractions from whole semen of $\mathrm{C}$. d. terrificus}

In order to obtain SF and MF, individual samples of whole semen were resuspended in $1 \mathrm{ml}$ of $10 \mathrm{mM}$ Tris-HCl buffer $(\mathrm{pH}$ 7.4), homogenized with a Teflon pestle in a glass potter (2 min at 800 r.p.m.) and ultracentrifuged $(100000 \mathrm{~g}$ for $35 \mathrm{~min}$; Hitachi model HIMAC CP56GII). The resulting supernatants correspond to the SF of whole semen. To avoid contamination with the SF, the resulting pellet was washed three times with the same buffer and was then homogenized (2 min at 800 r.p.m.) in $1 \mathrm{ml}$ of $10 \mathrm{mM}$ Tris- $\mathrm{HCl}$ buffer plus $0.1 \%(\mathrm{v} / \mathrm{v})$ Triton X-100 (Calbiochem, San Diego, CA, USA), and then ultracentrifuged (100 $000 \mathrm{~g}$ for $35 \mathrm{~min}$ ). The resulting supernatants correspond to the MF of whole semen. All steps were carried out at $4{ }^{\circ} \mathrm{C}$. SF and MF were stored in polystyrene tubes at $-80{ }^{\circ} \mathrm{C}$ until their use in LDH, protein, and peptidase activities assays. 


\section{Fractionation of semen of $\mathrm{C}$. d. terrificus}

In order to obtain SP, PR, and spermatozoa subcellular SF and MF of $C$. $d$. terrificus semen, the methodology described by Fernández et al. (2002) for human semen was adapted as follows. The pool of whole semen of five animals was homogenized in $1 \mathrm{ml}$ Tris-saline buffer (30 mM Trizma (Sigma) plus $130 \mathrm{mM} \mathrm{NaCl}$ (Merck), pH 7.4) and centrifuged (600 g for 20 min; Hitachi HIMAC CP56GII). The supernatant contained $\mathrm{SP}$ and PR and was reserved for later use, while the pellet contained spermatozoa. To avoid contamination with SPand PR, the pellet was washed with $1 \mathrm{ml}$ Tris-saline buffer and subsequently resuspended in $2.5 \mathrm{ml}$ of the same buffer and centrifuged (600 $\mathrm{g}$ for $10 \mathrm{~min}$ ). The resulting supernatant was discarded and the pellet was washed with $2.5 \mathrm{ml}$ Tris-saline buffer and subsequently resuspended in $2.5 \mathrm{ml}$ of the same buffer and centrifuged (1000 $\mathrm{g}$ for $15 \mathrm{~min}$ ). The supernatant was discarded, and the resulting pellet contained only spermatozoa. This pellet was homogenized in $2.5 \mathrm{ml} 10 \mathrm{mM}$ Tris- $\mathrm{HCl}$ buffer (pH 7.4; 2 min at 800 r.p.m.) and stored at $-80^{\circ} \mathrm{C}$, until use for separation of subcellular SF and MF. Then, the homogenate was sonicated (6 pulses of $30 \mathrm{~s}$, with intervals of $15 \mathrm{~s}$ ) and ultracentrifuged (100 $000 \mathrm{~g}$ for $35 \mathrm{~min}$ ). The pellet was reserved and the supernatant was ultracentrifuged (100 $000 \mathrm{~g}$ for $35 \mathrm{~min}$ ), and the resulting pellet was discarded while the supernatant was considered the spermatozoa subcellular SF. The reserved pellet from the penultimate ultracentrifugation was, then, homogenized at 800 r.p.m. (2 min, in $1 \mathrm{ml} 10 \mathrm{mM}$ Tris- $\mathrm{HCl}$ buffer) and ultracentrifuged (100 $000 \boldsymbol{g}$ for $35 \mathrm{~min}$ ). After discarding the resulting supernatant, the pellet was homogenized at 800 r.p.m. (2 min, in $1 \mathrm{ml} 10 \mathrm{mM}$ Tris-HCl buffer), and was considered as the spermatozoa subcellular MF.

The resulting supernatant from the first centrifugation (SP and PR) was centrifuged (1000 $\mathrm{g}$ for $20 \mathrm{~min}$ ) in order to eliminate debris and residual spermatozoa. The resulting pellet was discarded and the supernatant was stored at $-80{ }^{\circ} \mathrm{C}$. After defrost, this supernatant was ultracentrifuged $(100000 \mathrm{~g}$ for $120 \mathrm{~min}$ ). The obtained pellet was reserved and the supernatant was ultracentrifuged at the same conditions. The resulting pellet was discarded and the resulting supernatant contained SP. The reserved pellet from the penultimate ultracentrifugation was washed with $0.6 \mathrm{ml}$ Tris-saline buffer and subsequently resuspended in the same volume. To obtain $0.6 \mathrm{ml}$ more of this resuspension, all needful procedures were repeated with another pool of whole semen of five animals. Both the resuspensions were mixed $(1.2 \mathrm{ml})$, filtered in a membrane filter with a pore size $0.22 \mu \mathrm{m}$ (Millipore, Bedford, MA, USA), and then submitted to gel filtration in Sephadex G-200 (Sigma; $1.5 \times 30 \mathrm{~cm}$ ), at a flow rate of $0.16 \mathrm{ml} / \mathrm{min}$, in a column pre-equilibrated with Tris-saline buffer. The dead volume (Vo) was determined by injecting a solution of Blue dextran (Sigma). PR was not retained by the column (Fernández et al. 2002) and, then, was collected in the Vo (fractions 60-120 min or 9.6-19.2 ml), in a volume of about $9.6 \mathrm{ml}$. The eluate with PR was ultracentrifuged (100 $000 \mathrm{~g}$ for $120 \mathrm{~min}$ ) and the resultant pellet (PR fraction) was homogenized in $1 \mathrm{ml}$ Tris-saline buffer. All procedures were performed at $4{ }^{\circ} \mathrm{C}$. After obtaining SP, PR, SF, and MF of spermatozoa, samples were transferred to polystyrene tubes and maintained at $-80{ }^{\circ} \mathrm{C}$ until the measurements of protein and peptidase activities. Part of PR fraction was destined to the electron microscopy.

\section{Electron microscopy of $P R$ fraction}

The PR pellet was fixed for $2 \mathrm{~h}$ in a solution of $1.5 \%$ glutaraldehyde (Electron Microscopy Sciences-EMS, Hatfield, PA, USA) and $1 \%$ paraformaldehyde (Sigma) in $0.1 \mathrm{M}$ cacodylate buffer, $\mathrm{pH} 7.3$, and post-fixed in 1\% osmium tetroxide in the same buffer. After dehydration in ethanol graded series, the pellet was embedded in Embed-812 resin (Electron Microscopy SciencesEMS). Silver ultrathin sections were stained with uranyl acetate and lead citrate, examined and microphotographed (LEO 906E Transmission Electron Microscope, Zeiss, Göttingen, Germany).

\section{Protein}

Protein content was measured at $630 \mathrm{~nm}$ in triplicates by the method of Bradford (1976; Bio-Rad protein assay). Protein contents were extrapolated by comparison with standard curves of BSA (Sigma) in the same diluent.

\section{$L D H$}

As a marker for the fractionation procedure, LDH activity was determined (Bergmeyer \& Brent 1972) in samples of $3 \mu$ of SF and MF in triplicates incubated with $297 \mu \mathrm{l}$ of $\mathrm{NADH}(\beta-\mathrm{NADH}$, reduced form; Sigma), dissolved in $100 \mathrm{mM}$ phosphate buffer, $\mathrm{pH}$ 7.4, containing $1.6 \mathrm{mM}$ sodium pyruvate (Sigma) and $200 \mathrm{mM}$ $\mathrm{NaCl}$. Absorbance was read in 96-well flat bottom microplates, at 0 and $10 \mathrm{~min}$, in Bio-Tek PowerWave $\mathrm{X}$ spectrophotometer absorbance reader at $340 \mathrm{~nm}$. Values of LDH activity were obtained by subtracting the absorbance reading at $10 \mathrm{~min}$ from time zero of incubation at $37^{\circ} \mathrm{C}$, and extrapolated by comparison with a standard curve of $\mathrm{NADH}$ dissolved in $100 \mathrm{mM}$ phosphate buffer, pH 7.4, containing $200 \mathrm{mM} \mathrm{NaCl}$. LDH activity was expressed as $\mathrm{mmol} \mathrm{NADH}$ oxidized/min/mg protein.

\section{Peptidase activity assays}

Peptidase activities were quantified on the basis of the amount of 4-methoxy- $\beta$-naphthylamine (Sigma; for DPPIV and CAP) or $\beta$-naphthylamine (Sigma; for all other peptidases) released (Irazusta et al. 2001, Silveira et al. 2001, Gasparello-Clemente \& Silveira 2002, Gasparello-Clemente et al. 2003, Varona et al. 2003), which is the result of the enzyme activity of 20-50 $\mu \mathrm{l}$ samples incubated with prewarmed substrate solution at concentrations of $0.125 \mathrm{mM}$ (APA, APN-PS, APN-PI, CAP, PAP, PIP, and POP), $0.2 \mathrm{mM}$ (DPPIV), and $0.5 \mathrm{mM}$ (APB) in respective $0.05 \mathrm{M}$ buffers containing BSA $0.1 \mathrm{mg} / \mathrm{ml}$ in 96-well flat bottom microplates for $30 \mathrm{~min}$ at $37{ }^{\circ} \mathrm{C}$ in a total volume of $300 \mu \mathrm{l}$. The content of naphthylamine was estimated fluorometrically (microplate fluorescence reader Bio-Tek FL600FA) at $460 / 40 \mathrm{~nm}$ emission wavelength and 360/40 nm excitation wavelength. The fluorescence value obtained at time zero was subtracted from values at time $30 \mathrm{~min}$ and the relative fluorescence was then converted to picomoles of $\beta$-naphthylamine (Sigma) or 4-methoxy- $\beta$-naphthylamine (Sigma) by comparison with a correspondent standard curve, which was dissolved in the same diluent as the incubation.

Peptidase activities were expressed as picomoles of hydrolyzed substrate per min (U) per milligram of protein, in which 
the existence of a linear relationship between time of hydrolysis and protein content in the fluorometric assay was a previous condition. Considering enzyme activity measures as a comparative tool, the possible unspecific degradation during homogenization was not considered.

The following substrates and conditions were used:

- APA, L-aspartic acid $\alpha$-( $\beta$-naphthylamide; Sigma; solubilized in $0.012 \mathrm{M} \mathrm{NaOH}$ ) in Tris- $\mathrm{HCl}$ buffer, $\mathrm{pH} 7.4$, with $1 \mathrm{mM} \mathrm{MnCl}_{2}$;

- APB, L-arginine $\beta$-naphthylamide (Sigma; solubilized in $\mathrm{H}_{2} \mathrm{O}$ ) in phosphate buffer, pH 6.5, with $150 \mathrm{mM} \mathrm{NaCl}$, and $0.02 \mathrm{mM}$ puromycin (Sigma);

- APN, L-alanine- $\beta$-naphthylamide (Sigma; solubilized in $0.012 \mathrm{M} \mathrm{HCl}$ ) in phosphate buffer, $\mathrm{pH} 7.4$, with $1 \mathrm{mM}$ DTT (Sigma), with or without puromycin - APN-PI activity is the result of the incubation with puromycin, while $A P N-P S$ is the result of values of incubates without puromycin minus those with puromycin;

- CAP, H-Cys-4-methoxy- $\beta$-naphthylamide (Bachem Bioscience Inc., Torrance, CA, USA; solubilized in $0.012 \mathrm{M} \mathrm{HCl}$ ) Trismaleate, $\mathrm{pH}$ 5.9;

- DPPIV, Glycil-Proline-4-methoxy- $\beta$-naphthylamide (Bachem Bioscience Inc.; solubilized in dimethyl sulfoxide, DMSO (Sigma)) in Tris- $\mathrm{HCl}$ buffer, $\mathrm{pH} 8.3$;

- PAP-I, L-pyroglutamic acid- $\beta$-naphthylamide (Sigma; solubilized in DMSO) in phosphate buffer, $\mathrm{pH} 7.4$, with $2 \mathrm{mM}$ DTT (DTT inhibits PAP-II and actives PAP-I (O'Cuinn et al. 1990)) and 2 mM EDTA (Merck);

- PIP, L-proline- $\beta$-naphthylamide (Sigma; solubilized in DMSO) in phosphate buffer, $\mathrm{pH} 7.4$;

- POP, Z-Gly-Pro- $\beta$-naphthylamide (Bachem Bioscience Inc.;

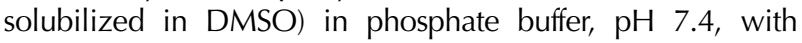
2 mM DTT.

\section{Characterization of peptidase activities in SF and MF of whole semen}

The characteristics of peptidase activities with their classical inhibitors

The susceptibilities of APA, APB, APN, CAP, DPPIV, PAP-I, and PIP peptidase activities were comparatively evaluated in a SF and/or MF pool of whole semen from 11 animals with: amastatin ([(2S,3R)-3-Amino-2- -5-methylhexanoyl]-Val-Val-Asp-OH.HCl; Bachem Bioscience Inc.): $0.026 \mathrm{mM}$ in acetic acid $8 \%$; bestatin ([(2S,3R)-3-Amino-2-hydroxy-4- phenylbutanoyl]-L-leucine; Bachem Bioscience Inc.): $0.026 \mathrm{mM}$ in acetic acid 8\%; diprotin A (H-Lle-Pro-Lle-OH; Bachem Bioscience Inc.): $0.026 \mathrm{mM}$ in deionized water; puromycin ( $3^{\prime}-[\alpha$-Amino- $p$-methoxyhydrocinnamamido]-3-deoxy- $N, N$-dimethyladenosine): $0.026 \mathrm{mM}$ in deionized water. The samples were incubated in the presence or absence of those substances, for $30 \mathrm{~min}$, at $25^{\circ} \mathrm{C}$, and peptidase activities were quantified.

The characteristics of peptidase activities with peptide hormones, DTT, EDTA, and $\mathrm{MnCl}_{2}$

The susceptibilities of APA, APB, APN, CAP, DPPIV, PAP-I, and PIP peptidase activities were comparatively evaluated in a SF and/or MF pool of whole semen from 11 animals with: $0.315 \mu \mathrm{M}$ Ang II (Sigma); $0.314 \mu \mathrm{M}$ AVT (reptilian analog of OXT and AVP; Sigma); $0.310 \mu \mathrm{M}$ BK (Sigma); $0.94 \mu \mathrm{M}$ FPP (Sigma); $0.94 \mu \mathrm{M}$ FPP $+1.8 \mathrm{mM} \mathrm{CaCl}_{2} ; 0.911 \mu \mathrm{M} \mathrm{TRH}$ (Sigma); $0.97 \mathrm{mM}$ DTT; $2 \mathrm{mM}$ EDTA; $1 \mathrm{mM} \mathrm{MnCl}_{2}$. The samples were incubated in the presence or absence of these substances, for $30 \mathrm{~min}$, at $25^{\circ} \mathrm{C}$, and peptidase activities were subsequently quantified.

\section{Statistical analysis}

Data were analyzed statistically using GraphPad Prism and Instat softwares (GraphPad Software Inc., San Diego, CA, USA). Regression analysis was performed to obtain standard curves. ANOVA, followed by Bonferroni test, compared values among all peptidase activities in the same seminal fraction. Student's $t$ test was performed to compare values of LDH between SF and $\mathrm{MF}$, and peptidase activities in different incubation conditions relative to the respective controls. Differences were considered statistically significant at a minimum level of $P<0.05$.

\section{Declaration of interest}

The authors declare that there is no conflict of interest that could be perceived as prejudicing the impartiality of the research reported.

\section{Funding}

This work was supported by Fundação de Amparo à Pesquisa do Estado de São Paulo - FAPESP, Brazil (research grant no. 04/14971-9). C E M (05/03745-0) and S C Y (07/06829-6) were recipients of a FAPESP fellowship.

\section{Acknowledgements}

The authors thank Valdir José Germano for his efficient technical assistance.

\section{References}

Agirregoitia E, Valdivia A, Carracedo A, Casis L, Gil J, Subiran N, Ochoa C \& Irazusta J 2006 Expression and localization of delta-, kappa-, and mu-opioid receptors in human spermatozoa and implications for sperm motility. Journal of Clinical Endocrinology and Metabolism 91 4969-4975.

Agrawal Y \& Vanha-Perttula T 1987 Effect of secretory particles in bovine seminal vesicles secretion on sperm motility and acrosome reaction. Journal of Reproduction and Fertility 79 409-419.

Akbarsha MA, Tamilarasan V, Kadalmani B \& Daisy P 2005 Ultrastructural evidence for secretion from the epithelium of ampulla ductus deferentis of the fan-throated lizard Sitana ponticeriana Cuvier. Journal of Morphology 266 94-111.

Albiston AL, Fernando R, Ye S, Peck GR \& Chai SY 2004 Alzheimer's, angiotensin IV and an aminopeptidase. Biological \& Pharmaceutical Bulletin 27 765-767.

Almeida-Santos SM \& Salomão MG 1997 Long-term sperm storage in the neotropical rattlesnake Crotalus durissus terrificus (Viperidae: Crotalinae). Japanese Journal of Herpetology 17 46-52. 
Almeida-Santos SM, Laporta-Ferreira IL, Antoniazzi MM \& Jared C 2004 Sperm storage in males of the snake Crotalus durissus terrificus (Crotalinae: Viperidae) in southeastern Brazil. Comparative Biochemistry and Physiology, Part A 139 169-174.

Amory JK \& Bremner WJ 2003 Regulation of testicular function in men: implications for male hormonal contraceptive development. Journal of Steroid Biochemistry and Molecular Biology 85 357-361.

Assinder SJ, Carey M, Parkinson T \& Nicholson HD 2000 Oxytocin and vasopressin expression in the ovine testis and epididymis: changes with the onset of spermatogenesis. Biology of Reproduction 63 448-456.

Barret AJ, Rawlings ND \& Woessner JF 1998 Handbook of Proteolytic Enzymes. London: Academic Press.

Bergmeyer HU \& Brent E 1972 Assay with pyruvate and NADH. In: Methods in Enzymatic Analysis, vol 2, pp 574-577. Ed HU Bergmeyer. London: Academic Press Inc.

Blaukat A 2003 Structure and signalling pathways of kinin receptors. Andrologia 35 17-23.

Bradford MM 1976 A rapid and sensitive method for the quantitation of microgram quantities of protein utilizing the principle of protein-dye binding. Analytical Biochemistry 72 248-254.

Cadel S, Pierotti AR, Foulon T, Créminon C, Barré N, Segrétain D \& Cohen P 1995 Aminopeptidase-B in the rat testes: isolation, functional properties and cellular localization in the seminiferous tubules. Molecular and Cellular Endocrinology 110 149-160.

Chatterjee S, Laloraya M \& Kumar PG 1997 Free radical-induced liquefaction of ejaculated human semen: a new dimension in semen biochemistry. Archives of Andrology 38 107-111.

Cockle SM, Prater GV, Thetford CR, Hamilton C, Malone PR \& Mundy AR 1994 Peptides related to thyrotrophin-releasing hormone (TRH) in human prostate and semen. Biochimica et Biophysica Acta 1227 60-66.

Constam DB, Tobler AR, Resing-Ehl A, Kemler I, Hersh LB \& Fontana A 1995 Puromycin-sensitive aminopeptidase. Sequence analysis, expression, and functional characterization. Journal of Biological Chemistry 270 26931-26939.

Cummins PM \& O'Connor B 1998 Pyroglutamyl peptidase: an overview of the three known enzymatic forms. Biochimica et Biophysica Acta 1429 $1-17$.

Davison JM, Sheills EA, Philips P, Barron WM \& Lindheimer MD 1993 Metabolic clearance of vasopressin and an analogue resistant to vasopressinase in human pregnancy. American Journal of Physiology 264 F348-F353.

El-Haggar S, El-Ashmawy S, Attia A, Mostafa T, Roaiah MM, Fayez A, Ghazi S, Zohdy W \& Roshdy N 2006 Beta-endorphin in serum and seminal plasma in infertile men. Asian Journal of Andrology 8 709-712.

Fernández JA, Heeb MJ, Radtke K-P \& Griffin JH 1997 Potent blood coagulant activity of human semen due to prostasome-bound tissue factor. Biology of Reproduction 56 757-763.

Fernández D, Valdivia A, Irazusta J, Ochoa C \& Casis L 2002 Peptidase activities in human semen. Peptides 23 461-468.

Fraser LR, Adeoya-Osiguwa SA, Baxendale RW \& Gibbons R 2006 Regulation of mammalian sperm capacitation by endogenous molecules. Frontiers in Bioscience 11 1636-1645.

García-Horsman JA, Männistö PT \& Venäläinen JI 2007 On the role of prolyl oligopeptidase in health and disease. Neuropeptides 41 1-24.

Gasparello-Clemente E \& Silveira PF 2002 Fluorometric assay using naphthylamide substrates for assessing novel venom peptidase activities. Toxicon 40 1617-1626.

Gasparello-Clemente E, Casis L, Varona A, Gil J, Irazusta J \& Silveira PF 2003 Aminopeptidases in visceral organs during alterations in body fluid volume and osmolality. Peptides 24 1367-1372.

Gibson AM, McDermott JR, Lauffart B \& Mantle D 1989 Specificity of action of human brain alanyl aminopeptidase on Leu-enkephalin and dynorphin-related peptides. Neuropeptides 13 259-262.

Green CM, Cockle SM, Watson PF \& Fraser LR 1996 A possible mechanism of action for fertilization promoting peptide, a TRH-related tripeptide that promotes capacitation and fertilizing ability in mammalian spermatozoa. Molecular Reproduction and Development 45 244-252.

Gribbins KM, Mills EM \& Sever DM 2007 Ultrastructural examination of spermiogenesis within the testis of the ground skink, Scincella laterale (Squamata, Sauria, Scincidae). Journal of Morphology 268 181-192.
Irazusta J, Silveira PF, Gil J, Varona A \& Casis L 2001 Effects of hydrosaline treatments on prolyl endopeptidase activity in rat tissues. Regulatory Peptides 101 141-147.

Irazusta J, Valdivia A, Fernández D, Agirregoitia E, Ochoa C \& Casis L 2004 Enkephalin-degrading enzymes in normal and subfertile human semen. Journal of Andrology 25 733-739.

Kawata S, Takayama S, Ninomiya K \& Makisumi S 1980 Porcine liver aminopeptidase B. Substrate specificity and inhibition by amino acids. Journal of Biochemistry 88 1601-1605.

Kravets FG, Lee J, Singh B, Trocchia A, Pentyala SN \& Khan SA 2000 Prostasomes: current concepts. Prostate 43 169-174.

Kugler P 1982 Aminopeptidase A is angiotensinase A. II. Biochemical studies on aminopeptidase $A$ and $M$ in rat kidney homogenate. Histochemistry 74 247-261.

Kühnel W \& Krisch B 1974 On the sexual segment of the kidney in the snake (Natrix natrix). Cell and Tissue Research 148 417-429.

Langlada FG, Santos S \& Ferreira ILL 1994 Tecniques of artificial insemination in Crotalus durissus terrificus (Viperidae-Crotalinae). Brazilian Journal of Veterinary Research and Animal Science 31 141-144.

Minelli A, Moroni M, Martínez E, Mezzasoma I \& Ronquist G 1998 Occurrence of prostasome-like membrane vesicles in equine seminal plasma. Journal of Reproduction and Fertility 114 237-243.

Minelli A, Allegrucci C, Mezzasoma I, Ronquist G, Lluis C \& Franco R 1999 CD26 and adenosine deaminase interaction: its role in the fusion between horse membrane vesicles and spermatozoa. Biology of Reproduction 61 802-808.

Mizutani S, Goto K, Nomura S, Ino K, Goto S, Kikkawa F, Kurauchi O, Goldstein G \& Tomoda Y 1993 Possible action of human placental aminopeptidase $\mathrm{N}$ in feto-placental unit. Research Communications in Chemical Pathology and Pharmacology 82 65-80.

Nakamura K, Fujiwara H, Higuchi T, Honda T, Yamada S, Nakayama T, Fujita J, Maeda M, Tachibana T, Suginami H et al. 1998 Bestatin, an aminopeptidase inhibitor, promotes follicular growth and ovulation suppressed by stress in mice. Journal of Endocrinology 45 547-553.

O'Cuinn G 1998 Peptide metabolism in cytoplasm of brain cells. Biochemical Society Transactions 26 279-292.

O'Cuinn G, O'Connor B \& Elmore M 1990 Degradation of thyrotropinreleasing hormone and luteinising hormone-releasing hormone by enzymes of brain tissue. Journal of Neurochemistry 54 1-13.

O'Hara BF, Donovan DM, Lindberg I, Brannock MT, Ricker DD, Moffatt CA, Klaunberg BA, Schindler C, Chang TS, Nelson RJ et al. 1994 Proenkephalin transgenic mice: a short promoter confers high testis expression and reduced fertility. Molecular Reproduction and Development $\mathbf{3 8}$ 275-284.

Olivo RA, Nascimento NG, Teixeira CFP \& Silveira PF 2008 Methotrexate and cyclosporine treatments modify the activities of dipeptidyl peptidase IV and prolyl oligopeptidase in murine macrophages. Clinical \& Developmental Immunology 2008794050 (doi: 10.1155/2008/794050).

Olsson I \& Ronquist G 1990 Nucleic acid association to human prostasomes. Archives of Andrology 24 1-10.

Ramírez M, Arechaga G, Garcia S, Sanchez B, Lardelli P \& Gandarias JM 1990 Mn2(+)-activated aspartate aminopeptidase activity, subcellular localization in young and adult rat brain. Brain Research $\mathbf{5 2 2}$ 165-167.

Riva A, Testa-Riva F, Usai E \& Cossu M 1982 The ampulla ductus deferentis in man, as viewed by SEM and TEM. Archives of Andrology 8 157-164.

Rónai AZ, Timár J, Makó E, Erdö F, Gyarmati Z, Tóth G, Orosz G, Fürst S \& Székely JI 1999 Diprotin A, an inhibitor of dipeptidyl aminopeptidase IV (EC 3.4.14.5) produces naloxone-reversible analgesia in rats. Life Sciences 64 145-152.

Sastry BV, Janson VE \& Owens LK 1991 Significance of substance P- and enkephalin-peptide systems in the male genital tract. Annals of the New York Academy of Sciences 632 339-353.

Sato Y 2003 Aminopeptidases and angiogenesis. Endothelium 10 287-290.

Sever DM 2004 Ultrastructure of the reproductive system of the black swamp snake (Seminatrix pygaea): IV. Occurrence of an ampulla ductus deferentis. Journal of Morphology 262 714-730.

Sever DM, Stevens RA, Ryan TJ \& Hamlett WC 2002 Ultrastructure of the reproductive system of the black swamp snake (Seminatrix pygaea): III. Sexual segment of the male kidney. Journal of Morphology 252 238-254. 
Silveira PF, Irazusta J, Gil J, Agirregoitia N \& Casis L 2001 Interactions among challenges of hydromineral balance, angiotensin-converting enzyme, and cystine aminopeptidase. Peptides 22 2137-2144.

Siviter RJ \& Cockle SM 1995 Peptides related to thyrotrophin-releasing hormone are degraded in seminal plasma by an enzyme similar to prolil endopeptidase. Journal of Endocrinology 144 61-66.

Subirán N, Agirregoitia E, Valdivia A, Ochoa C, Casis L \& Irazusta J 2008 Expression of enkephalin-degrading enzymes in human semen and implications for sperm motility. Fertility and Sterility 89 1571-1577.

Takahashi T, Ikai A \& Takahashi K 1989 Purification and characterization of proline-beta-naphthylamidase, a novel enzyme from pig intestinal mucosa. Journal of Biological Chemistry 264 11565-11571.

Talbot $\mathbf{P} 1991$ Compartimentalization in the acrosome. In Comparative Spermatology - 20 Years After, pp 255-259. Ed. B Baccetti. New York: Raven Press.

Tourmente M, Cardozo GA, Guidobaldi HA, Giojalas LC, Bertona M \& Chiaraviglio M 2007 Sperm motility parameters to evaluate the seminal quality of Boa constrictor occidentalis, a threatened snake species. Research in Veterinary Science 82 93-98.

Valdivia A, Irazusta J, Fernández D, Múgica J, Ochoa C \& Casis L 2004 Pyroglutamyl peptidase I and prolyl endopeptidase in human semen: increased activity in necrozoospermia. Regulatory Peptides 122 79-84.

Varona A, Silveira PF, Irazusta A, Valdivia A \& Gil J 2003 Effects of changes in hydromineral balance on rat brain aspartyl, arginyl, and alanyl aminopeptidase activities. Hormone and Metabolic Research 35 36-42.
Vivacqua A, Siciliano L, Sabato M, Palma A \& Carpino A 2004 Prostasome as zinc ligands in human seminal plasma. International Journal of Andrology 27 27-31.

Volsoe H 1944 Structure and seasonal variation of the male reproductive organs of Vipera berus (L.). Spolia Zoologica Musei Hauniensis V. Skrifter 5 1-157.

Zacariotti RL 2004 Estudo longitudinal do espermograma e dos níveis de testosterona sérica de cascavel (Crotalus durissus terrificus, Laurenti, 1768) proveniente da natureza do Estado de São Paulo. Dissertação (Mestrado em Reprodução Animal). Faculdade de Medicina Veterinária e Zootecnia, Universidade de São Paulo, São Paulo.

Zacariotti RL, Betkowsky SE, Grego KF, Santanna SS, Fernandes W, Oliveira CA \& Guimaraes MABV 2005 Spermogram and serum testosterone levels in wild caught Brazilian rattlesnakes (Crotalus durissus terrificus). Proceedings of the Annual Conference of The American Association of Zoo Veterinarians, 2005, Omaha, NE, USA pp 320.

Received 7 May 2008

First decision 30 May 2008

Revised manuscript received 1 September 2008

Accepted 10 September 2008 